\title{
A Study on the Comparison of Geometrical-Mechanical Intelligence Games Activities that are Conducted with Concrete Materials and in Computer Environment
}

\author{
Neşe Dokumacı Sütçü* \\ Faculty of Education, Dicle University, Diyarbakir, Turkey \\ ORCID: 0000-0003-3279-4194
}

\begin{tabular}{ll}
\hline \hline Article history & In this study it was aimed to determine the effect of geometrical- \\
Received: & mechanical intelligence games activities that are conducted with concrete \\
12.06 .2020 & materials and in computer environment on the spatial visualization and \\
Received in revised form: & mental rotation skills of prospective teachers and to examine the opinions \\
& of prospective teachers about the activities. The research was conducted \\
12.11 .2020 & with mixed-method research. The study group consists of 49 prospective \\
& teachers. The obtained quantitative data were collected with "Differential \\
Accepted: & Aptitude Test" and "Mental Rotation Test" and qualitative data were \\
18.11 .2020 & collected with "Open-Ended Questionnaire". In the analysis of obtained \\
Key words: & quantitative data, paired samples t-test and one-way analysis of \\
Computer environment, & covariance were used and in the analysis of qualitative data, content \\
Geomete materials, & analysis was used. According to the findings in the research, it was \\
intelligence game, & determined that the activities that are conducted both with concrete \\
Mental rotation, & materials and in computer environment significantly increased the spatial \\
Spatial visualization & visualization and mental rotation skills of prospective teachers. In \\
& addition to this, it was determined that there was not a difference between \\
the increases in the spatial visualization and mental rotation skills of & prospective teachers after the activities were conducted. Furthermore, \\
prospective teachers stated that they had fun while performing the & activities, the activities developed their visual/spatial intelligence, three- \\
dimensional thinking and establishing a part-whole relationship, & increased their attention and concentration and thought and decided faster \\
and more accurate in the second time they were answering the spatial & ability tests.
\end{tabular}

\section{Introduction}

We discover the world in which we live through images. Therefore, from birth, we need to have the ability to keep an image of the information in our minds about the objects and spaces that we live in which helps us to interact with the world around and to make sense of the world and to manipulate those meanings. This skill is called "Spatial Ability" in the literature.

\footnotetext{
*Correspondency: ndokumaci@dicle.edu.tr
} 
Spatial ability is the skill to create an image of the visual stimulus that we see around us in the mind and manipulate those images in the mind. Wang and Carr (2020) define spatial ability as the ability to mentally represent and manipulate two or three-dimensional images. Spatial ability is not a monolithic and static trait but consists of sub-skills that are related to each other and that can be developed throughout a person's life (Shamsuddin \& Din, 2016). For example, Linn and Petersen (1985) based on their meta-analysis study results, divided the spatial ability into three components as "spatial perception", "mental rotation" and "spatial visualization". The researchers defined the spatial perception component as the skill to determine spatial relations in respect to the orientation of one's own body or in the context of distracting information, described the mental rotation component as the skill to rotate two and three-dimensional figures quickly and accurately in one's mind, and expounded the spatial visualization component as the tasks that involve complex, multi-step manipulations of the information that are presented as spatial. Uttal et al.'s (2003) model makes use of two fundamental theoretical distinctions. The first is between intrinsic versus extrinsic information. Intrinsic information is the specification of the parts, and the relationship between the parts, that defines a particular object. In contrast, extrinsic information refers to the relation among objects in a group, relative to each other or to an overall framework. The second distinction is between static versus dynamic tasks. Dynamic tasks require movement such as moving, rotation, combining, bending, folding, or scaling. However, static tasks do not require movement (Uttal et al., 2013). Within this classification, four different categories of spatial ability are defined: Intrinsic-static, intrinsic-dynamic, extrinsic-static, and extrinsicdynamic spatial skills. Intrinsic-static skills involve "perceiving objects", intrinsic-dynamic skills include "assembling small units into larger ones, mentally rotating 2D or 3D objects and visualizing". Extrinsic-static skills consist of "understanding abstract spatial concepts" and extrinsic-dynamic skills involve "perspective taking" (Jung et al., 2020).

Classifications of spatial skills based on Linn and Petersen (1985) meta-analysis studies can be paired onto Uttal et al.'s (2013) model of spatial skills. For example, spatial visualization tasks, which are diverse in their nature, require both intrinsic-static and intrinsic-dynamic spatial skills while mental rotation and spatial perception fall into intrinsic-dynamic and extrinsic- static sub-domains respectively (Gilligan, 2019). In this research, the spatial visualization and mental rotation components of spatial ability were discussed. This owing to the fact that spatial visualization and mental rotation tests are commonly used to measure spatial ability. In that case Spatial Visualization Test (Differential Aptitude Test) and Mental Rotation Test were included as measures of intrinsic-dynamic spatial skills.

Spatial ability provides the opportunity to determine the locations of people in relation to the other objects in the space and to estimate the direction of a moving object (Freina \& Ott, 2014). Human beings use this ability every day. This ability is used when a written sentence or a verbal word are imagined, when an idea is formulated, when the result of a strategy or an incident is predicted, when something is planned or designed (Lord \& Rupert, 1995). In addition to this, spatial ability is quite important for the fields of science, technology, engineering, and mathematics (STEM) (Gilligan, Flouri \& Farran, 2017; Kuhl, Lim, Guerriero \& van Damme, 2019; Liu, Huang, Yu, \& Dou, 2020). For instance, the results of the research conducted by Atit et al. (2020), suggest that spatial skills play a significant role in middle school students' mathematics achievement. Delialioğlu and Aşkar (1999) determined that there is a positive, significant, and direct relationship between the spatial abilities of middle-school students and physics success. Pribyl and Bodner (1987) found that there is a positive and significant relationship between the spatial abilities of students and organic chemistry performances. Based on these results, developing the spatial abilities of students 
would form an appropriate base for increasing the success of students in STEM fields.

Scientific research that is conducted on spatial ability shows that a short period of training significantly increases the abilities of children and adults in this fields (Patkin, Shriki \& Barkai, 2018). As evident from the meta-analysis carried out by Yang, Liu, Chen, Xu and Lin (2019) and Uttal et al. (2013) spatial ability of people of all ages is malleable, and training generally has a positive and continuous impact on them. When the literature is surveyed about how the spatial ability which is an important skill both for children and adults, would be developed, it was found that researchers suggest different ideas. For example, according to Jirout and Newcombe (2015), playing with spatial toys and activities develop the spatial abilities of children. Because according to the researchers, children use spatial abilities while using a diagram for completing a Lego model and mentally rotating the jigsaw puzzles for matching the images of a jigsaw. Ha and Fang (2018) determined that the use of a technological tool called interactive virtual and physical manipulative improves the spatial abilities of middle school students. Renavitasari and Supianto (2018) stated that educational game tangram puzzle activities could be used to improve the spatial ability. Alexiou and Schippers (2018) stated that digital games facilitate the development of cognitive skills such as spatial skills. According to Toub, Verdine, Golinkoff, and Hirsh-Pasek (2019) an initial step towards providing early spatial education is ensuring access to toys like shape sorters, blocks, puzzles, and origami that lend themselves to spatial play.

According to Ministry of National Education [MoNE] (2013), geometrical-mechanical intelligence games can be used effectively as the means of improving the spatial skills of the students. Geometrical-mechanical intelligence games are games which can be played single, mutual or as a team. While playing these games, the player makes use of geometrical thinking methods, spatial thinking skills, hand eye coordination or motor skills. Pre-established game materials and digital environments can be used in most of the games. The examples of these games include tangram, polyomino, cube counting, making shape, maze games, node games, Rubik's cube, mikado, jenga and puzzles.

In this research, by using geometrical-mechanical intelligence games for the development of spatial ability, the tasks in the games were presented to students in two different physical forms as concrete materials and in computer environment (virtual environment). Computer manipulative are often similar to concrete manipulative (Bouck \& Falnagan, 2010). Both physical and virtual manipulative are one of the supportive instructional tools used in teaching (Gecu-Parmaksiz, \& Delialioglu, 2019). A major difference between concrete and computer manipulative is their physical nature (Gibson, 1962). Concrete manipulative can be touched, held, and rearranged physically. Computer manipulative are available via computer and closely resemble concrete manipulative but can only be manipulated and moved on the screen (Spencer, 2008). The computer manipulative are more interactive than a picture or video, but provides less sense stimuli than a concrete manipulative. In other words, concrete manipulative give children tactile experiences unlike computer manipulative (Olkun, 2003). On the other hand intensive training in computer environment may create deeper spatial understanding than concrete manipulative because of the opportunity to encourage students to think about spatial problems, manipulate objects directly, and navigate around in virtual environments (Osberg, 1997).

In the literature, studies that examine whether or not using concrete materials as geometricalmechanical intelligence games have any effect on students' spatial abilities have shown that these games are not related to the students' spatial abilities (Caldera et al., 1999; Grimshaw, 
Sitarenios \& Finegan, 1995), while other research results (Brosnan, 1998; Jirout \& Newcombe, 2015; Levine, Ratliff, Huttenlocher \& Cannon, 2011; Newman, Hansen \& Gutierrez, 2016) have generally shown that these games are effective in the development of spatial abilities. The results of the research examining the effects of geometrical-mechanical intelligence games played in virtual environment on the development of spatial ability (Alexiou \& Schippers, 2018; Lin \& Chen, 2016; Liu, Huang, Yu \& Dou, 2020; Martin-Dorta et al., 2014; Moreau, 2013, Okagaki \& Frensch, 1994; Osberg, 1997; Yang \& Chen, 2010) show that such games are effective in the development of spatial ability. When the research that compares the effects on the development of spatial ability of geometrical-mechanical intelligence games played in the form of concrete materials and virtual environments (Olkun, 2003; Spencer, 2008; Thompson, 2016) is analyzed, it is seen that different results have been reached. In a research conducted by Olkun (2003), the effects of tangram game which was played in computer environment and as a concrete material, on the two-dimensional spatial visualization skills of primary school students were compared and after the application, although significant increases were determined in the two-dimensional spatial visualization skills of both groups, it was revealed that this increase was a bit more in experimental group where Tangram game was played in computer environment, but this difference was not statistically significant. In Spencer's (2008) research, the effects of concrete material and digital tangram games on the two-dimensional visualization skills of primary school teacher candidates were researched and as a result of the study, it was observed that significant improvements took place in the two-dimensional visualization skills of teacher candidates. In Thompson's (2016) study, the effects of concrete, virtual and multimodal tangram usages on the spatial skills of primary school students were examined. In the research, it was revealed that there was a statistically significant difference between the spatial skill pre and post-test scores of virtual tangram group, however, there was not $t$ a statistically significant difference between the pre and post-test scores of concrete and multimodal tangram groups. In addition to this, in the research the post-test scores of the groups were compared with each other and it was determined that there was not a statistically significant difference between them.

In the literature, it was revealed that the geometrical-mechanical intelligence games, which are played in the form of concrete materials or in virtual environments, usually have a positive effect on the development of spatial ability. As it can be seen, there is limited numbers of research which compares the efficiency of geometrical-mechanical intelligence games that are played with concrete materials and in virtual environments; they mostly focus on primary school students, concentrate upon tangram and therefore reach different conclusions. Developing the spatial abilities of secondary school students who are in the period of abstract processing is extremely important in terms of supporting their daily activities and academic success. In this respect, it is important to develop the spatial abilities of the mathematics teacher candidates who will educate secondary school students. On the other hand, the Intelligence Games Course has been taught in secondary schools as an elective course in our country within the body of the MoNE since the 2012-2013 academic year. The Intelligence Games Course Curriculum is designed as a flexible framework program that needs to be structured by teachers rather than a standard program. Research conducted on the Intelligence Games Course (Adalar \& Yüksel, 2017; Aslan, 2019; Sargın \& Taşdemir, 2020) revealed that teachers had difficulties in practicing intelligence games. At the same time, the training will guide prospective teachers to the geometric-mechanical intelligence games unit of the program. According to the MoNE (2013), pre-built game tools and digital environments can be used in most of the games. For this reasons, in this research, it was aimed to compare in which environment the spatial visualization and mental rotation skills of prospective teachers are effective and beneficial by using the Katamino, Q.bitz Extreme and Architecto which are 
geometrical-mechanical intelligence games, in both physical forms and to examine the opinions of prospective teachers about the activities. With this aim, the research questions of the study are as follows:

- What is the effect of geometrical-mechanical intelligence games activities on the spatial visualization and mental rotation skills of prospective teachers?

- What are the opinions of prospective teachers on the geometrical-mechanical intelligence games activities?

\section{Methods}

\section{Research Design}

In this research, embedded design among mixed research designs which include both qualitative and quantitative data, was used. This design can be used under conditions which necessitate adding a qualitative component in a research which is mainly quantitative or to add a quantitative component in a research which is mainly qualitative. For example, a researcher can embed qualitative data in a quantitative method such as experimental design or can embed quantitative data in a qualitative method such as case study (Creswell \& PlanoClark, 2007). As it can be seen in this research, most of the research in the literature shows that qualitative data is embedded in quantitative data (Creswell, 2012). In this research, the effect of geometrical-mechanical intelligence games activities on the spatial visualization and mental rotation skills of prospective teachers was put forward with quantitative data and the opinions of prospective teachers on the activities were put forward with qualitative data. The quantitative part of the research was designed in one-group pre-test-post-test experimental design and conducted with two experimental groups. Experimental patterns are used to measure variables and to reveal cause-effect relationships between these variables (Çepni, 2014). Two pre-tests were applied before conducting the geometrical-mechanical intelligence games activities and two post-tests were applied after the application of activities. The qualitative part was obtained from the answers of prospective teachers to open-ended questions after the application.

\section{Participants}

The convenience sampling method was used in selecting the study group. The convenience sampling is a type of nonprobability or nonrandom sampling method, where members of the target population have a certain set of practical criteria such as availability at a given time period, easy accessibility, geographical proximity or the willingness to participate in the study (Dörnyei, 2007). Convenience sampling is fast, affordable, easy, and applicable to both qualitative and quantitative studies (Etikan, Musa \& Alkassim, 2016). The study group which was chosen with this method, consists of 49 prospective teachers who are studying in the A and B sections third grade of Department of Mathematics Education in a state university in Turkey in the academic year of 2017-2018. Experimental groups were randomly selected in two existing sections and experimental-I group consists of 25 prospective teachers (16 females, 9 males) and experimental-II group consists of 24 prospective teachers (18 females, 6 males). In experimental-I group, geometrical-mechanical intelligence games activities were conducted with concrete materials and in experimental-II group geometrical-mechanical intelligence games activities were conducted in computer environment. 


\section{Data Collection Tools}

In the research, the spatial visualization skills of prospective teachers were measured with Differential Aptitude Test, mental rotation skills were measured with Mental Rotation Test and their opinions about the activities were measured with open-ended questionnaire.

Differential Aptitude Test was developed by Bennett, Seashore and Wesman (1974). The test consists of 60 questions that include the development of three-dimensional objects. The quality of each question is the same. As the development in each question is folded, it is asked which object in the choices would be created. The given development is always the outlook of the object. Each question has four choices and one correct answer. The scoring is conducted by erasing an accurate answer for each three wrong answers. Sample question of the Differential Aptitude Test is given in Figure 1.

1.

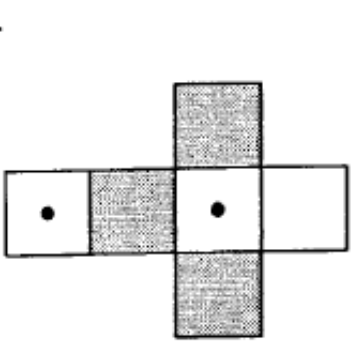

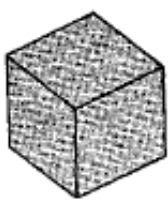

A

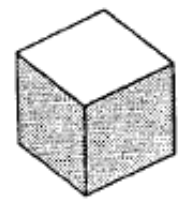

B

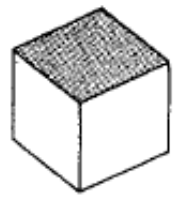

C

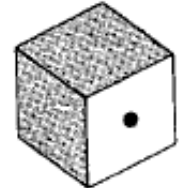

D

Figure 1. Sample Question of the Differential Aptitude Test

Mental Rotation Test was developed by Vandenberg and Kuse (1978) and reorganized by Peters et al. (1995). The test consists of 24 questions. The quality of each question is the same. Each question is based on predicting the new form of a shape which is created by cube units after it is rotated into different directions and different angles. Each question has four choices and two correct answers. While scoring, if the two correct answers are found one point is obtained and if only one answer is found or none of them are found, zero point is obtained. Sample question of the Mental Rotation Test is given in Figure 2.

$1 . \mathrm{a}$

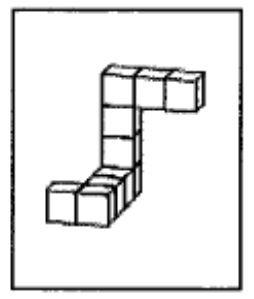

1

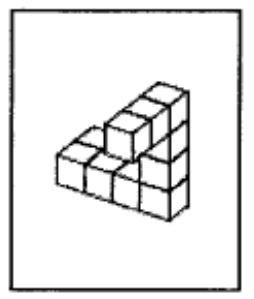

2

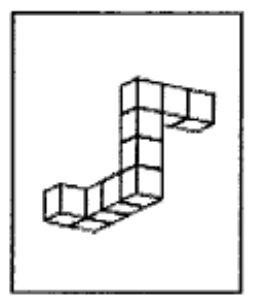

3

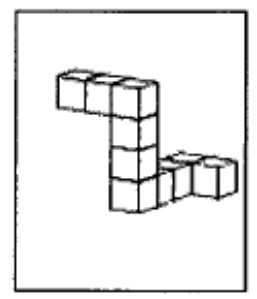

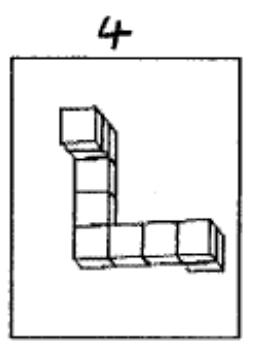

Figure 2. Sample Question of the Mental Rotation Test

In the context of this research, the reliability of Differential Aptitude Test which measures the spatial visualization skills of prospective teachers was found as .901; the reliability of Mental Rotation Test which measures the mental rotation skills of prospective teachers was found as 903. In general, tests with a reliability coefficient value of .70 and above are considered reliable (Büyüköztürk, 2011; Urbina, 2004). Therefore, it can be said that the tests used in this research are reliable.

The open-ended questionnaire was prepared by the researcher by taking into consideration the opinions of three faculty members working in the field of mathematics education and pilot 
scheme was conducted with the prospective teachers. One of the questions in the open-ended questionnaire is as follows: "What are your opinions about the intelligence games activities? What kind of effect did the activities have on you?"

\section{Games and Developing Them in Computer Environment}

In the research, Katamino, Q.bitz Extreme and Architecto games which are geometrical-mechanical intelligence games and appropriate to the levels of adults were utilized. The reason for these games to be chosen is that they are in the category of geometrical-mechanical intelligence games and require the use of spatial skills. Katamino, Q.bitz Extreme and Architecto games, which are sold in the market were purchased as concrete materials with the support of Dicle University Scientific Research Projects Coordinator's Office. Katamino, Q.bitz Extreme and Architecto games to be used in this study were developed by the cooperation of the researchers and a computer engineer, in the way to be the same as the games in the market. For the development of games, Blender, Paint.Net, Unity 3D 5.3. 1f1 version, C\# and Microsoft Visual Studio programs were used. The following is the brief information on the development process of the games.

(1) Blender, which is a free three-dimensional modelling and animation program for tissue dressing, was used.

(2) Paint.Net, which is a free image and photo editing program for user interfaces and design, was used.

(3) After all the modelling and designs were prepared, they were transferred to version 5.3.1f1 of Unity 3D, which is a free gaming engine, and part and UI (User Interface) designs were created on Unity 3D.

(4) In Visual Studio environment, games were coded with $\mathrm{C}$ \#.

(5) The compilation of the game was made to be played on the computer.

\section{Implementation Process}

The implementation lasted for nine weeks as two hours per week. Before the implementation, Differential Aptitude and Mental Rotation Test was applied as pre-test to the experimental groups. Katamino, Q.bitz Extreme and Architecto games were applied on experimental-I and experimental-II groups for three weeks for each game. The tasks in the games were presented as beginner, medium and advanced by taking into consideration the rules of the games. The applications performed in the experimental study process were the same for experimental-I and experimental-II group. The only difference between them was that the tasks assigned to the experimental-I group are presented to the students with concrete materials and the tasks assigned to the experimental-II group were presented on the computer environment. After the implementation of nine weeks, same tests were applied on experimental groups as post-test. Furthermore, open-ended questionnaire was applied on prospective teachers at the end of the implementation. Information about games and application process is given below.

In Katamino game, each student was given 12 pentominoes in different colors, 1 playground, 1 separatrix and 1 game booklet. Pentamino is the shape which is created by adjoining five squares which has at least one common edge and penta is the group that consists of pentaminoes which completes a rectangle area that is formed in the location of separatrix. Each pentaminoes occupy a place of five-unit squares in the playground. The purpose in the game is to complete the penta by using pentaminoes. As the number of required penta increases, the number of pentamino that would be used increase as well. Therefore, the 
difficulty of the task increases equally. For example, for penta 3, the separatrix is placed between 3 and 4. In the rectangular area, which is limited with the separatrix, three pieces of pentamino are placed appropriately. Katamino game was applied on experimental-I and experimental-II group in three levels. It was required from prospective teachers to create penta $3,4,5$ in beginner level, to create penta $6,7,8,9$ in medium level and to create penta $10,11,12$ in advanced level by using the pentaminoes in the manual and the ones they chose. Katamino game which was given in two different physical forms as concrete material and in computer environment and the implementation images of the game were given in Table 1.

Table 1. Katamino game and the implementation images

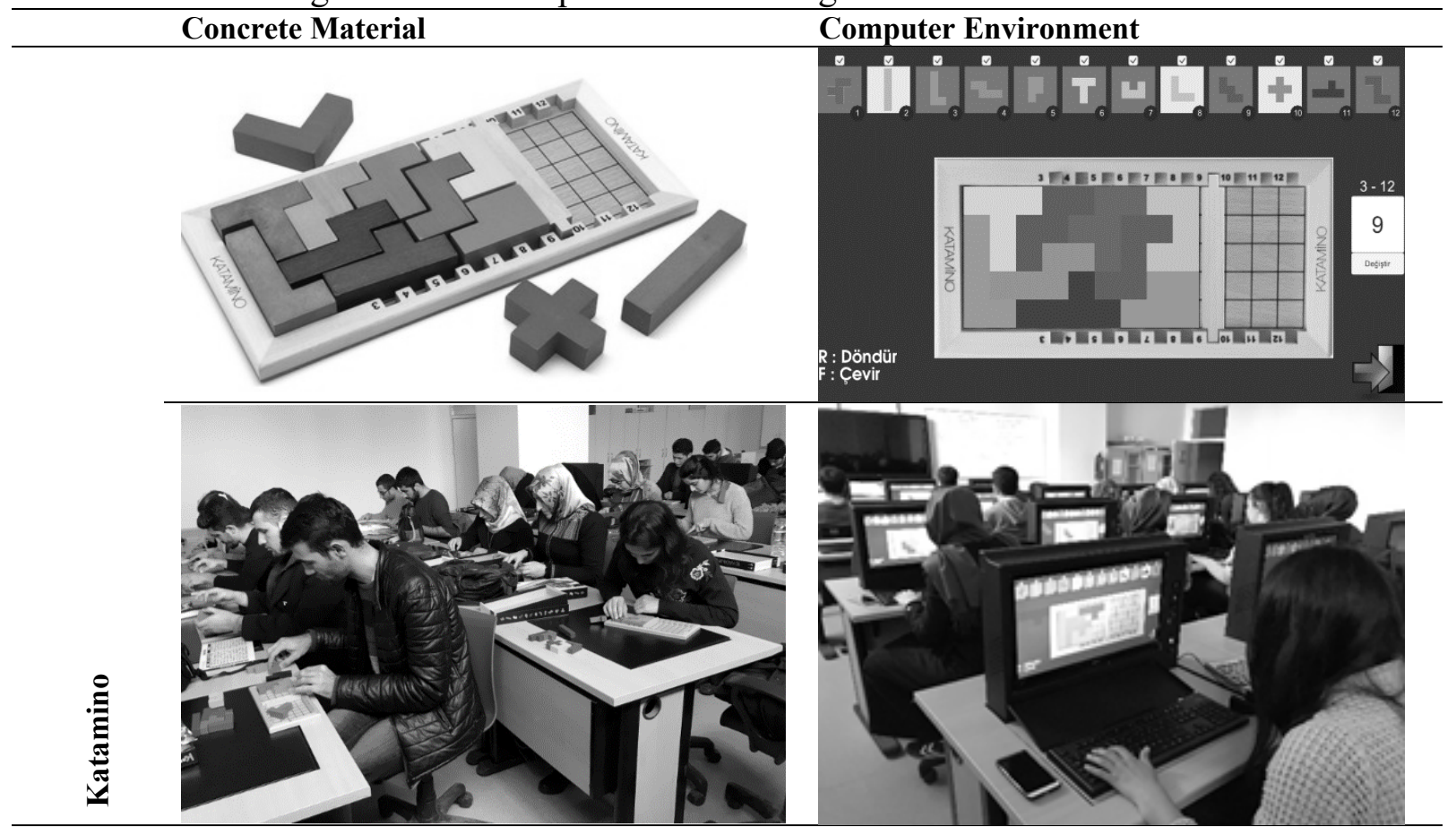

In Q.bitz Extreme game, each student was given a table, 16 pieces of cube and game cards. 14 of the cubes are the same and the other 2 cubes are same with one another. In each surface of the cubes there are different shapes. The purpose of the game is to make the same designs on the game cards by using the 16 cubes. Q.bitz Extreme games were applied on experimental-I and experimental-II groups in three levels. In the beginner and medium level, prospective teachers were required to create the designs in the game card in a way that the complexity of the cards would increase. In advanced level, students are required to create the design on the randomly chosen game card as much as they remember after examining them in the given period. Q.bitz Extreme game which was given in two different physical forms as concrete material and in computer environment and the implementation images of the game were given in Table 2. 
Table 2. Q.bitz extreme game and the implementation images

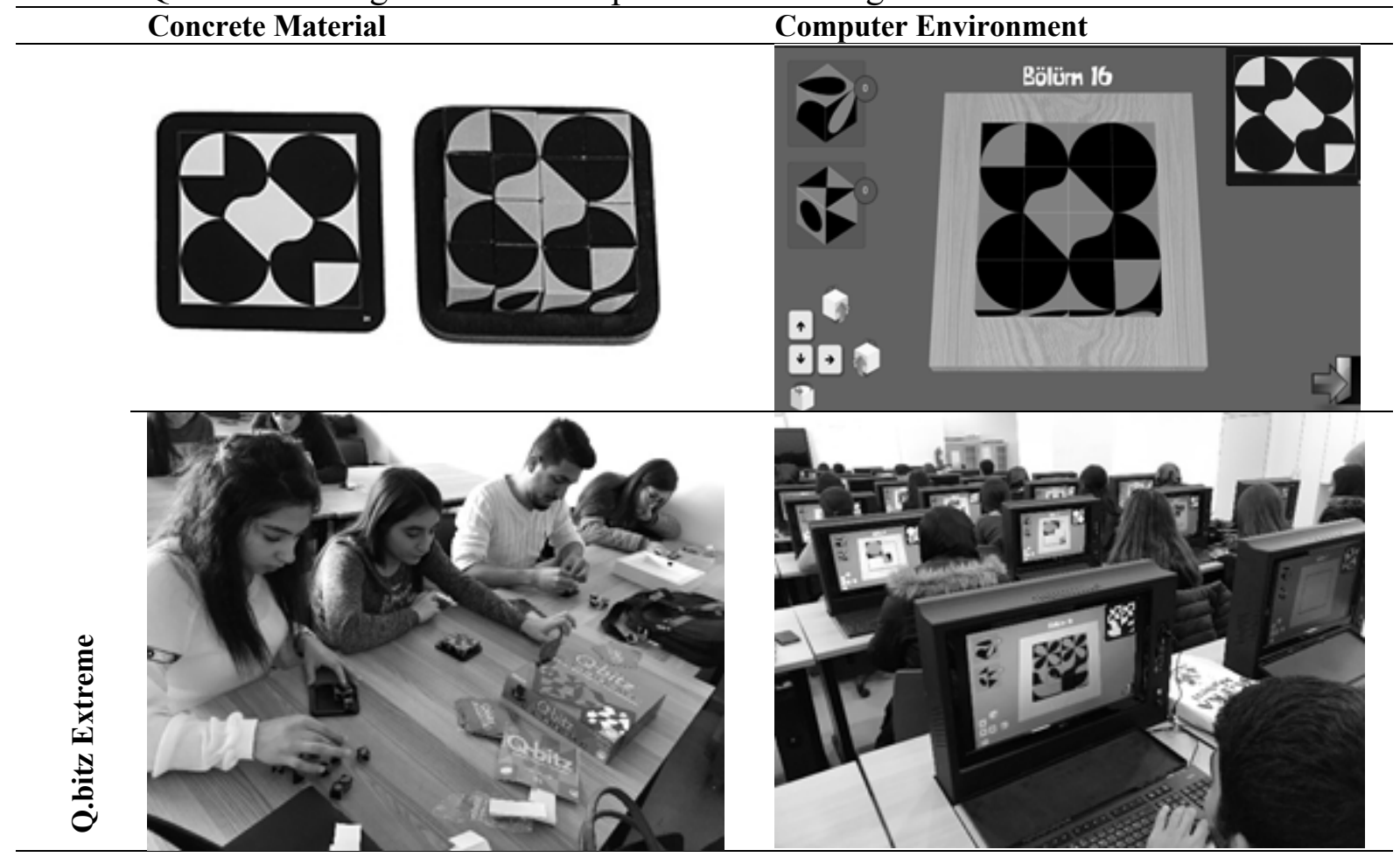

In Architecto game, each student was given 18 building blocks and 1 booklet. Building blocks are three-dimensional geometrical shapes which are proportional with each other such as cubes, cylinders, rectangular prisms and bridges. The purpose in the game is to create threedimensional models with given building blocks for each model in the booklet. The type and number of blocks which would be used in the structuring of each model are shown in a window under each page. There are six difficulty levels, starting from yellow (easy) to red (difficult). Architecto was applied on experimental-I and experimental-II groups in three levels. In the beginner level, prospective teachers were required to make the models in the difficulty level of yellow and orange in the manual, in medium level they were required to make the models in the difficulty level of green and blue, in advanced level they were required to make the models in the difficulty level of purple and red. Architecto game which was given in two different physical forms as concrete material and in computer environment and the implementation images of the game were given in Table 3. 
Table 3. Architecto game and the implementation images

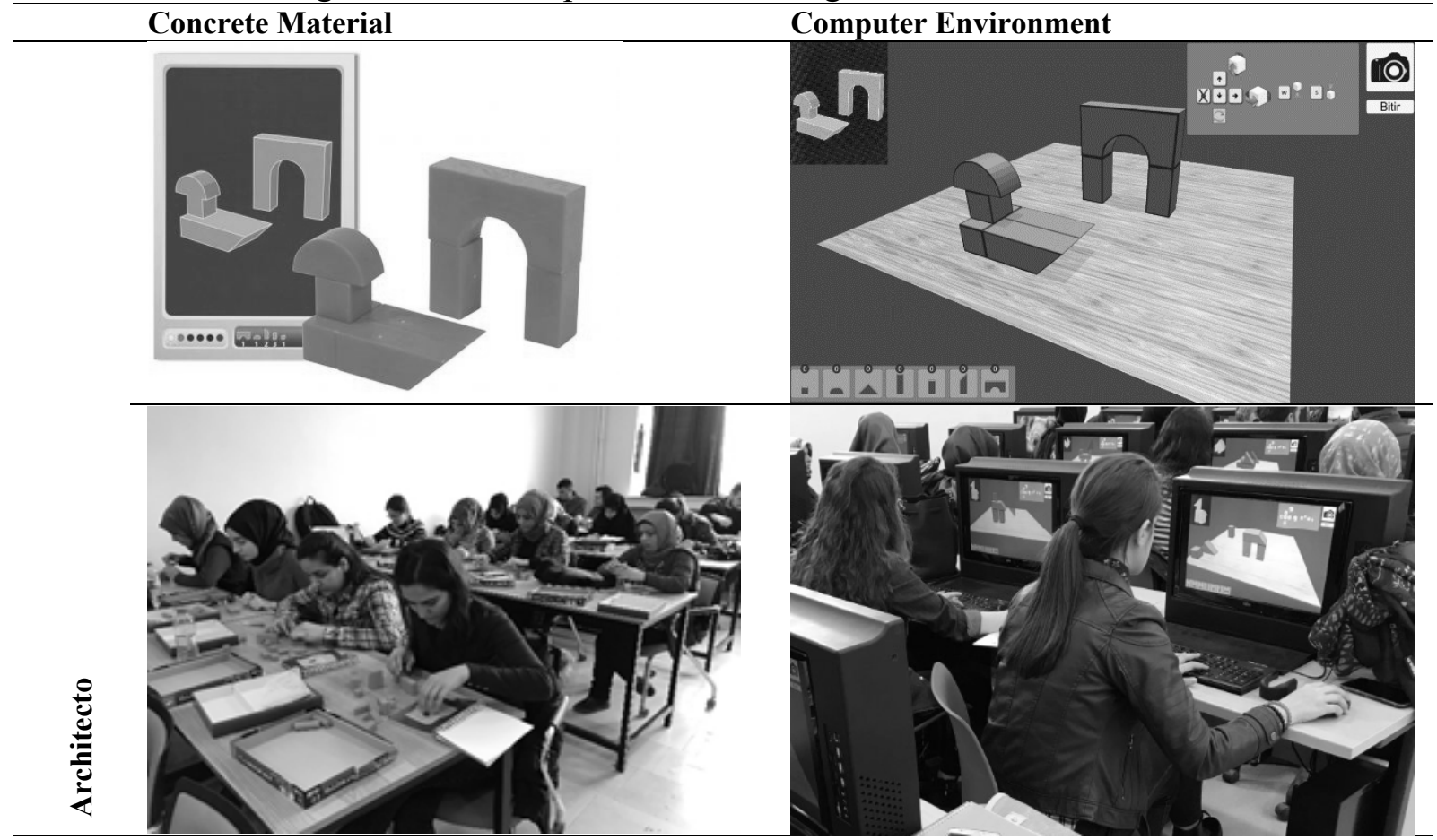

\section{Data Analysis}

In the analysis of obtained quantitative data, paired samples t-test and one-way analysis of covariance were used and in the analysis of qualitative data, content analysis was used.

The "SPSS 21" package program was used in the analysis of the quantitative data which were obtained from the research. The value of .05 was taken as the level of significance. One of the analyses that can be used in the comparison of pre-test and post-test score means of experimental groups is paired samples $t$-test. The paired samples $t$-test is a parametric test performed to determine whether there is a statistically significant difference between the averages of the data values obtained from two consecutive measurement results on the same data source (Can, 2014). In order to use paired samples $t$-test, it is required for the data set which consist of the differences between the pre-test and post-test scores of students, to show normal distribution. Since the number of students in the group was less than 50, the ShapiroWilk test was used to test whether the difference scores obtained showed normal distribution characteristics. In addition, the histogram, normal Q-Q, box-line charts and the kurtosis and skewness values were examined and whether the scores exhibited normal distribution was determined (Büyüköztürk, 2011; Can, 2014). According to Shapiro-Wilk test, since $p>.05$ for the spatial visualization test ( $p=.224$ for experimental-I and $p=.106$ for experimental-II) and for the mental rotation test ( $p=.661$ for experimental-I and $p=.549$ for experimental-II) and since histogram, normal Q-Q, box-line charts, kurtosis and skewness values show normal distribution, the assumption of paired samples $t$-test was met.

One-way analysis of covariance was used for the significance of the difference between the post-test scores that were corrected according to the pre-test scores of prospective teachers in experimental groups. The covariance analysis is a statistical process in which the effect of an independent variable is controlled, and its mean values are compared (Can, 2014). In order to conduct this analysis, scores of dependent variable for each of these groups should show 
normal distribution and variances should be homogeneous; there should be a linear relationship between the scores of dependent variable and control variable; regression coefficients in the groups should be homogeneous; control variable and independent variable should be independent from each other (Büyüköztürk, 2011; Can, 2014). According to Shapiro-Wilk Test, since $p>.05$ for the spatial visualization test $(p=.755$ for experimental-I and $p=.091$ for experimental-II) and for the mental rotation test $(p=.174$ for experimental-I and $p=.160$ for experimental-II) and since histogram, normal Q-Q, box-line charts, kurtosis and skewness values show normal distribution, the assumption of normality was met. According to Levene test, since $\mathrm{p}>.05$ for spatial visualization test $(p=.071)$ and for mental rotation test $(p=.098)$, the assumption of the variances' homogeneity was met. With basic linear regression, it was revealed that there is a positive relationship between the post-test score which is the dependent variable and pre-test score which is the control variable of the groups for spatial visualization test $(r=.859$ for experimental-I and $r=.678$ for experimentalII) and for mental rotation test ( $r=.671$ for experimental-I and $r=.727$ for experimental-II) and after the examination of scatter diagram, it was also revealed that these relationships were linear. With general linear model, it was determined that the inclinations of regression lines were homogeneous since $\mathrm{p}>.05$ for spatial visualization test $(p=.413)$ and for mental rotation test $(p=.784)$. Lastly, with one-way variance analysis, it can be stated that control variable and independent variable were independent from each other since $\mathrm{p}>.05$ for spatial visualization test $(p=.887)$ and for mental rotation test $(p=.189)$. As it can be seen, all of the assumptions were met in order to use one-way analysis of covariance.

Content analysis was used in the analysis of qualitative data. The content analysis gathers similar data within the framework of certain concepts and themes and interprets them in a way that the reader can understand (Yıldırım \& Şimşek, 2011). The categories were created by coding the answers of prospective teachers to each question in the open-ended questionnaire and were presented in tables with the frequencies and percentages.

\section{Results}

$T$-test results regarding the comparison of spatial visualization and mental rotation pre-test and post-test score averages of prospective teachers in experimental-I group were given in Table 4.

Table 4. T-test results in experimental-I group

\begin{tabular}{|c|c|c|c|c|c|c|c|}
\hline Experimental-I & & $\mathrm{N}$ & Mean & Std. Deviation & $\mathrm{df}$ & $\mathrm{t}$ & Sig. \\
\hline \multirow{2}{*}{ Spatial Visualization } & Pre-test & 25 & 29.03 & 11.36 & \multirow{2}{*}{24} & \multirow{2}{*}{-4.820} & \multirow{2}{*}{.000} \\
\hline & Post-test & 25 & 34.68 & 10.45 & & & \\
\hline \multirow{2}{*}{ Mental Rotation } & Pre-test & 25 & 10.28 & 5.77 & \multirow{2}{*}{24} & \multirow{2}{*}{-4.256} & \multirow{2}{*}{.000} \\
\hline & Post-test & 25 & 14.44 & 6.23 & & & \\
\hline
\end{tabular}

When Table 4 is examined, it is observed that the spatial visualization pre-test score averages of prospective teachers in experimental-I group is 29.03 and their score averages increase to 34.68 after the activities that were conducted with concrete materials. In the $t$-test result, a statistically significant difference was found $\left[t_{(24)}=-4.820, p<.05\right]$ between the pre-test and post-test score averages of prospective teachers in experimental-I group. According to this, it can be stated that activities that were conducted with concrete materials significantly increase the spatial visualization skills of prospective teachers. Similarly, according to Table 4, it is observed that the mental rotation pre-test score averages of prospective teachers in experimental-I group is 10.28 and their score averages increase to 14.44 after the activities that were conducted with concrete materials. In the $t$-test result, a statistically significant 
difference was found $\left[t_{(24)}=-4.256, p<.05\right]$ between the pre-test and post-test score averages of prospective teachers in experimental-I group. According to this, it can be stated that activities that were conducted with concrete materials significantly increase the mental rotation skills of prospective teachers.

$T$-test results regarding the comparison of spatial visualization and mental rotation pre-test and post-test score averages of prospective teachers in experimental-II group were given in Table 5.

Table 5. T-test results in experimental-II group

\begin{tabular}{llllllll}
\hline Experimental-II & & $\mathrm{N}$ & Mean & Std. Deviation & df & t & \multirow{2}{*}{ Sig. } \\
\hline \multirow{2}{*}{ Spatial Visualization } & Pre-test & 24 & 28.54 & 12.38 & \multirow{2}{*}{2.348} & \multirow{2}{*}{.028} \\
\cline { 2 - 7 } & Post-test & 24 & 33.18 & 11.70 & \multirow{2}{*}{23} & \multirow{2}{*}{-4.798} & \multirow{2}{*}{.000} \\
\hline \multirow{2}{*}{ Mental Rotation } & Pre-test & 24 & 12.29 & 4.71 & & \\
\cline { 2 - 6 } & Post-test & 24 & 15.88 & 5.13 & & &
\end{tabular}

As shown in Table 5, it is observed that the spatial visualization pre-test score averages of prospective teachers in experimental-II group is 28.54 and their score averages increase to 33.18 after the activities that were conducted in computer environment. In the $t$-test result, a statistically significant difference was found $\left[t_{(23)}=-2.348, p<.05\right]$ between the pre-test and post-test score averages of prospective teachers in experimental-II group. According to this, it can be stated that activities that were conducted in computer environment significantly increase the spatial visualization skills of prospective teachers. Similarly, according to Table 5 , it is observed that the mental rotation pre-test score averages of prospective teachers in experimental-II group is 12.29 and their score averages increase to 15.88 after the activities that were conducted in computer environment. In the $t$-test result, a statistically significant difference was found $\left[t_{(23)}=-4.798, p<.05\right]$ between the pre-test and post-test score averages of prospective teachers in experimental-II group. According to this, it can be stated that activities that were conducted in computer environment significantly increase the mental rotation skills of prospective teachers.

The difference between the spatial visualization and mental rotation post-test scores that were corrected according to the pre-test scores of prospective teachers in experimental groups was examined with one-way analysis of covariance. Post-test score averages that were corrected according to the spatial visualization and mental rotation pre-test scores of prospective teachers in experimental groups were given in Table 6.

Table 6. Post-test score averages of prospective teachers

\begin{tabular}{lllll}
\hline & Groups & $\mathrm{N}$ & Mean & Corrected Mean \\
\hline \multirow{2}{*}{ Spatial Visualization } & Experimental-I & 25 & 34.68 & 34.51 \\
\cline { 2 - 5 } & Experimental-II & 24 & 33.18 & 33.36 \\
\hline \multirow{2}{*}{ Mental Rotation } & Experimental-I & 25 & 14.44 & 15.18 \\
\cline { 2 - 5 } & Experimental-II & 24 & 15.88 & 15.11 \\
\hline
\end{tabular}

According to Table 6, the spatial visualization post-test score averages of prospective teachers in experimental groups were 34.68 for experimental-I and 33.18 for experimental-II groups, mental rotation post-test score averages were 14.44 for experimental-I and 15.88 for experimental-II groups. However, when the pre-test scores of the groups are controlled, it can be seen that there are changes in their post-test scores. The corrected spatial visualization post-test score averages of prospective teachers in experimental groups were 34.51 for experimental-I and 33.36 for experimental-II groups, the corrected mental rotation post-test 
score averages were 15.18 for experimental-I and 15.11 for experimental-II groups. The results of one-way analysis of covariance which was conducted in order to determine whether or not the difference between the corrected spatial visualization and mental rotation post-test score averages of prospective teachers in experimental groups was significant were given in Table 7.

Table 7. The results of one-way analysis of covariance

\begin{tabular}{lllllll}
\hline & Source & Sum of Squares & df & Mean Square & F & Sig. \\
\hline \multirow{4}{*}{ Spatial Visualization } & Pre-test & 3343.926 & 1 & 3343.926 & 63.429 & .000 \\
\cline { 2 - 7 } & Group & 16.324 & 1 & 16.324 & .310 & .581 \\
\cline { 2 - 7 } & Error & 24.25 .065 & 46 & 52.719 & & \\
\cline { 2 - 7 } & Corrected Total & 5796.522 & 48 & & & \\
\hline \multirow{5}{*}{ Mental Rotation } & Pre-test & 737.319 & 1 & 737.319 & 42.424 & .000 \\
\cline { 2 - 7 } & Group & .065 & 1 & .065 & .004 & .952 \\
\cline { 2 - 7 } & Error & 799.466 & 46 & 17.380 & & \\
\cline { 2 - 7 } & Corrected Total & 1562.000 & 48 & & & \\
\hline
\end{tabular}

When Table 7 is examined, the difference between the spatial visualization post-test score averages that were corrected according to pre-test scores of prospective teachers in experimental groups, was not significant $\left[F_{(1,46)}=.310, p>.05\right]$. According to this finding, there was not a significant difference between the increases of spatial visualization skills of prospective teachers in experimental groups after the implementations. As shown in Table 7, the difference between the mental rotation post-test score averages that were corrected according to pre-test scores of prospective teachers in experimental groups, was not significant $\left[F_{(1,46)}=.004, p>.05\right]$. According to this finding, there was not a significant difference between the increases of mental rotation skills of prospective teachers in experimental groups after the implementations.

The opinions of prospective teachers in experimental-I group about the activities that were conducted with concrete materials were summarized under three categories and the results were given in Table 8 .

Table 8. The opinions of prospective teachers in experimental-I group

\begin{tabular}{llll}
\hline Category & Code & $\mathrm{f}$ & $\%$ \\
\hline & Having fun & 18 & 72.00 \\
& Developing visual/spatial intelligence & 16 & 64.00 \\
& Developing three-dimensional thinking skill & 15 & 60.00 \\
& Increasing the attention and concentration & 15 & 60.00 \\
& Developing the skill of establishing a part-whole relation & 13 & 52.00 \\
& Developing the skill of quick thinking and deciding & 12 & 48.00 \\
Advantages & Developing the skill of thinking and deciding correctly & 12 & 48.00 \\
& Learning to be persistent or not give up in difficult levels & 11 & 44.00 \\
& Increasing the self-confidence & 5 & 20.00 \\
& Developing the skill of versatile thinking & 5 & 20.00 \\
& Improving the memory & 4 & 16.00 \\
& Developing the skill of thinking thoroughly & 2 & 8.00 \\
& Increasing the creativity & 2 & 8.00 \\
\hline \multirow{2}{*}{ Disadvantages } & Experiencing difficulty in the beginning of the games & 6 & 28.00 \\
& Having difficulty in abstract thinking & 6 & 28.00 \\
& Experiencing stress when not succeeding as the difficulty levels increase & 5 & 24.00 \\
\hline & This kind of applications should be more frequent & 18 & 72.00 \\
Suggestions & Different intelligence games should be played as well & 16 & 64.00 \\
& The application duration should be longer & 13 & 52.00 \\
& These practices should be applied in other lessons & 12 & 48.00 \\
\hline
\end{tabular}


When Table 8 is examined in terms of advantages, prospective teachers stated that they had fun during the activities that were conducted with concrete materials, the activities developed their visual/spatial intelligence, three-dimensional thinking and established a part-whole relationship, increased their attention and concentration. In addition to these, at the end of the activities, prospective teachers expressed that they thought and decided faster and were more accurate while answering the spatial ability tests for the second time when compared to the first time and they were persistent to complete the tasks as the difficulty of the tasks became more difficult and they did not give up when they could not complete the tasks. When Table 8 is examined in terms of disadvantages, prospective teachers stated that they had difficulty in abstract thinking and when they first started to do the activities and experienced stress when they could not succeed as the difficulty levels of the tasks increased. When Table 8 is examined in terms of suggestions, prospective teachers stated that this kind of activities should be conducted more frequently, different intelligence games should be played, application duration should be longer, and these practices should be applied in other lessons.

The opinions of prospective teachers in experimental-II group about the activities that were conducted in computer environment were summarized under three categories and the results were given in Table 9.

Table 9. The opinions of prospective teachers in experimental-II group

\begin{tabular}{llll}
\hline Category & Code & $\mathrm{f}$ & $\%$ \\
\hline & Having fun & 19 & 79.17 \\
& Developing three-dimensional thinking skill & 18 & 75.00 \\
& Developing visual/spatial intelligence & 17 & 70.83 \\
& Increasing the attention and concentration & 14 & 58.33 \\
& Developing the skill of thinking and deciding correctly & 13 & 54.17 \\
\multirow{4}{*}{ Advantages } & Developing the skill of quick thinking and deciding & 11 & 45.83 \\
& Developing the skill of establishing a part-whole relation & 10 & 41.67 \\
& Learning to be persistent or not give up in difficult levels & 7 & 29.17 \\
& Improving the memory & 6 & 25.00 \\
& Increasing the creativity & 5 & 20.83 \\
& Increasing the self-confidence & 2 & 8.33 \\
& Developing the logical/mathematical intelligence & 2 & 8.33 \\
\hline \multirow{3}{*}{ Disadvantages } & Having difficulty in abstract thinking & 12 & 50.00 \\
& Experiencing stress when not succeeding as the difficulty levels increase & 10 & 41.67 \\
& Experiencing difficulty in the beginning of the games & 9 & 37.50 \\
& Lots of unsuccessful trials & 7 & 29.17 \\
\hline \multirow{2}{*}{ Suggestions } & Different intelligence games should be played as well & 12 & 50.00 \\
& These practices should be applied in other lessons & 11 & 45.83 \\
\hline
\end{tabular}

When Table 9 is examined in terms of advantages, prospective teachers stated that they had fun during the activities that were conducted in computer environment, the activities developed their visual/spatial intelligence, three-dimensional thinking and established a partwhole relationship, increased their attention and concentration. In addition to these, at the end of the activities, prospective teachers stated that they thought and decided faster and were more accurate while answering the spatial ability tests for the second time when compared to the first time. When Table 9 is examined in terms of disadvantages, prospective teachers stated that they had difficulty in abstract thinking and when they first started to do the activities and experienced stress when they could not succeed as the difficulty levels of the tasks increased and were unsuccessful although they tried lots of times When Table 9 is examined in terms of suggestions, prospective teachers stated that different intelligence games should be played and these practices should be applied in other lessons. 


\section{Discussion, Conclusions and Suggestions}

In this research, it was revealed that activities that were conducted both with concrete materials and in computer environment, significantly developed the spatial visualization and mental rotation skills of prospective teachers. This finding shows similarities with the results of certain research in the literature. For example, Spencer (2008) determined that concrete and digital tangram games made significant progresses in the two-dimensional visualization skills of primary prospective. Ha and Fang (2018) determined that the use of a technological tool called interactive virtual and physical manipulative improves the three-dimensional spatial visualization skills of middle school students. VanMeerten et al. (2019) investigated the effects of a mobile puzzle game on three-dimensional mental rotation skills of students in a study. As the result of this research, it was determined that a mobile puzzle game training led to significant improvements in three-dimensional mental rotation skills. Alexiou and Schippers (2018) stated that digital games facilitate the development of cognitive skills such as spatial skills, enhanced mental rotation abilities. In their study, Martin-Dorta et al. (2014) designed a three-dimensional mobile game called as "Virtual Blocks" in order to develop the mental rotation skills of first grade engineering students and these game applications demonstrated that they have a positive effect on the mental rotation skills of students. Moreau (2013) compared the effects of education that is based on two and three-dimensional block video game on the mental rotation tasks of university students and as a result of the research, while two-dimensional block video game education developed the two-dimensional mental rotation tasks of students, three-dimensional video game education caused increases both in two and three-dimensional mental rotation tasks. In their study, Martin-Gutierrez et al. (2009) analyzed the relationship between the spatial visualization and mental rotation skills of first grade engineering students with their use of Tetris video game and the findings of the study indicate that receiving video game education had a positive effect on the spatial visualization and mental rotation skills of students. In their study, Okagaki and Frensch (1994) examined the effect of playing Tetris on the spatial visualization and mental rotation skills and task completion durations of university students and at the end of the research, they determined a decrease in the task completion durations of students both in spatial visualization and mental rotation tasks and in parallel to this, they determined increases in the spatial visualization and mental rotation performances of students.

In this research, it was determined that after the practices, there was not $t$ a significant difference between the developments of spatial visualization and mental rotation skills of prospective teachers in experimental groups where activities were conducted both with concrete materials and in computer environment asboth physical and virtual manipulative are one of the supportive instructional tools used in teaching (Gecu-Parmaksiz, \& Delialioglu, 2019). Similarly, Thompson (2016) examined the effects of concrete and virtual tangram usage on the development of spatial sense and revealed that there was nott a difference between the post-test scores of the groups. In a research by Olkun (2003) the effects of tangram game that was played both in computer environment and with concrete materials on the two-dimensional spatial visualization skills of experimental groups were compared and after the application, it was revealed that, although a significant increase was determined in the two-dimensional spatial visualization skills of both groups, the difference between them was not statistically significant. This finding is in compliance with the opinions of Durmuş and Karakirik (2006) on the virtual and concrete manipulative. According to Durmuş and Karakirik (2006), since virtual manipulative is the actual model of concrete manipulative, virtual manipulative can provide as much engagement as concrete manipulative. Since there is not a significant difference between the activities that were conducted with concrete materials 
and in computer environment in the development of spatial visualization and mental rotation skills of prospective teachers, it can be stated that activities that are conducted with concrete materials and in computer environment can substitute each other.

According to the qualitative findings of the research, prospective teachers in the experimental groups in which activities were conducted both with concrete materials and in computer environment, stated that they had fun during the activities and the activities developed their visual/spatial intelligence, three-dimensional thinking establishing a part-whole relationship. Including game activities in the lessons for which activities were conducted both with concrete materials and in computer environment and providing a different and entertaining environment in which prospective teachers can manipulate various geometrical shapes can be shown as the reasons of this finding. Because these activities provide the opportunity to develop their spatial abilities such as selecting geometrical shapes, rotating the chosen shapes to fit for a purpose, integrating and separating as well as having fun. Thus, Reifel and Gereenfield (1983) stated that children's classroom play with building blocks is a good source for learning about part-whole relations. In addition to this, prospective teachers stated that due to activities that were conducted with concrete materials and in computer environment increased their attention and concentration and at the end of the activities, prospective teachers in both groups stated that they thought and decided faster and more were accurate for the second time they answered the spatial ability tests, when compared to first time. Furthermore, they stated that they were persistent to complete the tasks as the difficulty of the tasks became more difficult and they did not give up when they could not complete the tasks. When compared to the other group, a higher number of prospective teachers who performed the activities in computer environment stated that they had difficulty in abstract thinking, experienced stress when they could not succeed as the difficulty levels of the tasks increased and were unsuccessful although they tried several times. The reason of this finding may derive from the fact that, since concrete materials were not used in activities that were performed in computer environment, these activities required a relatively advanced level of abstraction compared to activities that were conducted with concrete materials. Thus, according to Verhaegh et al. (2009), since concrete materials do not reduce the dimensionality to a flat screen, they provide more visual-spatial freedom and add different tactual experiences. When student interacts with a concrete manipulative, he/she can sense the 3D shape of the model through both vision and touch, all perceptual depth cues are available and the movements that he/she makes with his/her hands to manipulate the model are congruent with what he/she sees. In contrast, virtual manipulative typically lacks perceptual depth cues and the interface to most current virtual manipulative is a keyboard or mouse, so that interaction with the interface is usually incongruent with movement of the real viewed object (Arsenault \& Ware, 2004; Ware \& Rose, 1999). These disharmonies between the vision and haptic cues, can be shown as the reason of activities that were conducted in computer environment to be more compelling compared to activities that were conducted with concrete materials for prospective teachers.

Based on the obtained findings, activities that are conducted both with concrete materials and in computer environment can be utilized in the development of spatial visualization and mental rotation skills of prospective teachers. Studies that are devoted to developing the spatial ability can be conducted by taking the preferences of students into consideration about the activities that are performed with concrete materials and in computer environment. Comparative studies which examine the effectiveness of activities that are conducted both with concrete materials and in computer environment on other spatial abilities can be conducted with different sample groups. Studies that are devoted to developing different 
cognitive abilities can be conducted with intelligence games.

\section{References}

Adalar, H., \& Yuksel, I. (2017). Intelligence games curriculum from social studies, science and other branch teachers' point of view. Electronic Turkish Studies, 12(28), 1-23.

Alexiou, A., \& Schippers, M. C. (2018). Digital game elements, user experience and learning: A conceptual framework. Education and Information Technologies, 23(6), 2545-2567.

Arsenault, R., \& Ware, C. (2004). The importance of stereo and eye-coupled perspective for eye-hand coordination in fish tank VR. Presence: Teleoperators \& Virtual Environments, 13(5), 549-559.

Aslan, M. (2019). Examination of problems experienced by teachers teaching mind games courses. Scientific Educational Studies, 3(1), 56-73.

Atit, K., Power, J. R., Veurink, N., Uttal, D. H., Sorby, S., Panther, G., Msall, C., Fiorella, L., $\&$ Carr, M. (2020). Examining the role of spatial skills and mathematics motivation on middle school mathematics achievement. International Journal of STEM Education, 7(1), 1-13.

Bennett, G. K., Seashore, H. G., \& Wesman, A. G. (1974). Manual for the differential aptitude tests: Forms $s$ and $t$. New York: The Psychological Corporation.

Borriello, G. A., \& Liben, L. S. (2017). Encouraging maternal guidance of preschoolers' spatial thinking during block play. Child Development, 1-14.

Bouck, E. C., \& Flanagan, S. M. (2010). Virtual manipulatives: What they are and how teachers can use them. Intervention in School and Clinic, 45(3), 186-191.

Brosnan, M. J. (1998). Spatial ability in children's play with Lego blocks. Perceptual and Motor Skills, 87, 19-28.

Büyüköztürk, Ş. (2011). Data analysis handbook for social science. Turkey: Pegem Academy Publishing.

Caldera, Y. M., Mc Culp, A., O'Brien, M., Truglio, R. T., Alvarez, M., \& Huston, A. C. (1999). Children's play preferences, construction play with blocks, and visual-spatial skills: Are they related? International Journal of Behavioral Development, 23(4), 855872.

Can, A. (2014). Quantitative data analysis in the process of scientific research with SPSS. Turkey: Pegem Academy Publishing.

Çepni, S. (2014). Introduction to research and project studies. Trabzon, Turkey: Celepler Publishing.

Creswell J. W. (2012). Educational research: Planning, conducting, and evaluating quantitative and qualitative research. Boston (MA): Allyn \& Bacon.

Creswell, J. W., \& Plano-Clark, V. L. (2007). Designing and conducting mixed methods research. Thousand Oaks, CA: Sage Publication.

Delialioğlu, Ö., \& Aşkar, P. (1999). Contribution of students' logical thinking ability, mathematical skills and spatial ability on achievement in secondary school physics. Hacettepe University Journal of Education, 16-17, 34-39.

Dörnyei, Z. (2007). Research methods in applied linguistics. New York: Oxford University Press.

Durmuş, S., \& Karakirik, E. (2006). Virtual manipulatives in mathematics education: A theoretical framework. Turkish Online Journal of Educational Technology, 5(1), 1-7.

Etikan, I., Musa, S. A., \& Alkassim, R. S. (2016). Comparison of convenience sampling and purposive sampling. American journal of theoretical and applied statistics, 5(1), 1-4.

Freina, L., \& Ott, M. (2014). Discussing implementation choices for serious games supporting spatial and orientation skills. ICERI2014 Proceedings (pp. 5182-5191). 
Gecu-Parmaksiz, Z., \& Delialioglu, O. (2019). Augmented reality-based virtual manipulatives versus physical manipulatives for teaching geometric shapes to preschool children. British Journal of Educational Technology, 50(6), 3376-3390.

Gibson, J.J. (1962). Observations on active touch. Psychological Review, 69(6), 477-491.

Gilligan, K. (2019). Space for mathematics: Spatial cognition as a contributor to the development of mathematics skills in children. Unpublished doctoral dissertation, University College London.

Gilligan, K. A., Flouri, E., \& Farran, E. K. (2017). The contribution of spatial ability to mathematics achievement in middle childhood. Journal of experimental child psychology, 163, 107-125.

Grimshaw, G. M., Sitarenios, G., \& Finegan, J. A. K. (1995). Mental rotation at 7 years: Relations with prenatal testosterone levels and spatial play experiences. Brain and Cognition, 29(1), 85-100.

Ha, O., \& Fang, N. (2018). Interactive virtual and physical manipulatives for improving students' spatial skills. Journal of Educational Computing Research, 55(8), 10881110 .

Jirout, J. J., \& Newcombe, N. S. (2015). Building blocks for developing spatial skills: Evidence from a large, representative US sample. Psychological science, 26(3), 302310.

Jung, S., Meinhardt, A., Braeuning, D., Roesch, S., Cornu, V., Pazouki, T., Schiltz, C., Lonnemann, J., \& Moeller, K. (2020). Hierarchical development of early visual-spatial abilities-a taxonomy based assessment using the magrid app. Frontiers in Psychology, 11.

Kuhl, P. K., Lim, S. S., Guerriero, S., \& van Damme, D. (2019). Shapes, blocks, puzzles and origami: From spatial play to STEM learning. In Developing Minds in the Digital Age.

Levine, S. C., Ratliff, K. R., Huttenlocher, J., \& Cannon, J. (2011). Early puzzle play: A predictor of preschoolers' spatial transformation skill. Developmental Psychology, $48(2), 530$.

Lin, C. H., \& Chen, C. M. (2016). Developing spatial visualization and mental rotation with a digital puzzle game at primary school level. Computers in Human Behavior, 57, 23 30 .

Linn, M. C., \& Petersen, A. C. (1985). Emergence and characterization of gender differences in spatial abilities: A meta-analysis. Child Development, 56, 1479-1498.

Liu, X., Huang, H., Yu, K., \& Dou, D. (2020). Can video game training improve the twodimensional mental rotation ability of young children? In International Conference on Human-Computer Interaction (pp. 305-317). Springer, Cham.

Lord, T. R., \& Rupert, J. L. (1995). Visual-spatial aptitude in elementary education majors in science and math tracks. Journal of Elementary Science Education, 7(2), 47-58.

Martin-Dorta, N., Sanchez-Berriel, I., Bravo, M., Hernandez, J., Saorin, J. L., \& Contero, M. (2014). Virtual blocks: A serious game for spatial ability improvement on mobile devices. Multimedia Tools and Applications, 73(3), 1575-1595.

Martin-Gutierrez, J., Saorin, J. L., Martin-Dorta, N., \& Contero, M., (2009). Do video games improve spatial abilities of engineering students? International Journal of Engineering Education, 25(6), 1194-1204.

Ministry of National Education [MoNE]. (2013). Intelligence games lesson curriculum for middle school. Ankara, Turkey.

Moreau, D. (2013). Differentiating two-from three-dimensional mental rotation training effects. The Quarterly Journal of Experimental Psychology, 66(7), 1399-1413.

Newman, S. D., Hansen, M. T., \& Gutierrez, A. (2016). An fMRI study of the impact of block building and board games on spatial ability. Frontiers in Psychology, 7. 
Okagaki, L., \& Frensch, P. A. (1994). Effects of video game playing on measures of spatial performance: Gender effects in late adolescence. Journal of Applied Developmental Psychology, 15(1), 33-58.

Olkun, S. (2003). Comparing computer versus concrete manipulatives in learning 2D geometry. Journal of Computers in Mathematics and Science Teaching, 22(1), 43-46.

Osberg, K. M. (1997). Spatial cognition in the virtual environment. Technical Report-97 18, Seattle: Human Interface Technology Laboratory, University of Washington.

Patkin, D., Shriki, A., \& Barkai, R. (2018). Strategies applied by pre-service elementary school mathematics teachers for coping with tasks that require a mental rotation. International Journal of Science and Mathematics Education, 1-22.

Peters, M., Laeng, B., Latham, K., Jackson, M., Zaiyouna, R., \& Richardson, C. (1995). A redrawn Vandenberg and Kuse mental rotations test: Different versions and factors that affect performance. Brain and Cognition, 28, 39-58.

Pribyl, J. R., \& Bodner, G. M. (1987). Spatial ability and its role in organic chemistry: A study of four organic courses. Journal of Research in Science Teaching, 24(3), 229240.

Reifel, S., \& Greenfield, P. M. (1983). Part-whole relations: Some structural features of children's representational block play. Child care quarterly, 12(2), 144-151.

Renavitasari, I. R. D., \& Supianto, A. A. (2018). Educational game for training spatial ability using tangram puzzle. In 2018 International Conference on Sustainable Information Engineering and Technology (SIET) (pp. 174-179). IEEE.

Sargın, M. \& Taşdemir, M. (2020). Assessment of elective intelligence games course curriculum by teachers (A Case Study). Electronic Journal of Social Sciences, 19(75), 1444-1460.

Shamsuddin, N.A.A., \& Din, S.C. (2016). Spatial ability skills: A correlation between Augmented Reality (AR) and conventional way on wayfinding system. EnvironmentBehaviour Proceedings Journal, 1(2), 159-167.

Spencer, K. T. (2008). Preservice elementary teachers' two-dimensional visualization and attitude toward geometry: Influences of manipulative format (Unpublished doctoral dissertation). University of Florida.

Thompson, T. (2016). The effects of concrete, virtual, and multimodal tangram manipulatives on second grade elementary students' mathematics achievement and development of spatial sense: A convergent parallel mixed methods study (Unpublished doctoral dissertation). Oklahoma State University.

Toub, T. S., Verdine, B. N. Golinkoff, R.M. \& Hirsh-Pasek, K. (2019). Shapes, blocks, puzzles and origami: From spatial play to STEM learning. In Developing Minds in the Digital Age towards a Science of Learning for 21st Century Education, Educational Research and Innovation, OECD Publishing, Paris (pp.177-186).

Urbina, S. (2004). Essentials of psychological testing. New Jersey: John Wiley \& Sons. Inc.

Uttal, D. H., Meadow, N. G., Tipton, E., Hand, L. L., Alden, A. R., Warren, C., \& Newcombe, N. S. (2013). The malleability of spatial skills: A meta-analysis of training studies. Psychological bulletin, 139(2), 352.

Vandenberg, S.G. \& Kuse, A.R. (1978). Mental rotations, a group test of three dimensional spatial visualization. Perceptual and Motor Skills, 47, 599-604.

VanMeerten, N., Varma, K., Gravelle, M., Miller, N., Kraikul, E., \& Fatemi, F. (2019). Evidence of a relationship between mental rotation skills and performance in a 3D puzzle game. In Frontiers in Education (Vol. 4, p. 82). Frontiers.

Verhaegh, J., Resing, W. C. M., Jacobs, A. P. A., \& Fontijn, W. F. J. (2009). Playing with blocks or with the computer? Solving complex visual-spatial reasoning tasks: 
Comparing children's performance on tangible and virtual puzzles. Educational and Child Psychology, 26(3), 18.

Wang, L., \& Carr, M. (2020). Understanding the relationship between spatial ability and mathematics achievement through the lens of information processing theory. North American Journal of Psychology, 22(2), 173-192.

Ware, C., \& Rose, J. (1999). Rotating virtual objects with real handles. ACM Transactions on Applied Perception (TAP), 6, 162-180.

Yang, J. C., \& Chen, S. Y. (2010). Effects of gender differences and spatial abilities within a digital pentominoes game. Computers and Education, 55(3), 1220-1233.

Yang, W., Liu, H., Chen, N., Xu, P., \& Lin, X. (2020). Is early spatial skills training effective? A Meta-analysis. Frontiers in Psychology, 11.

Yıldırım, A., \& Şimşek, H. (2011). Qualitative research methods in the social sciences. Ankara: Seçkin Publishing. 